\title{
IUCrJ
}

Volume 8 (2021)

Supporting information for article:

Rapid response to emerging biomedical challenges and threats

Marek Grabowski, Joanna M. Macnar, Marcin Cymborowski, David R. Cooper, Ivan G. Shabalin, Miroslaw Gilski, Dariusz Brzezinski, Marcin Kowiel, Zbigniew Dauter, Bernhard Rupp, Alexander Wlodawer, Mariusz Jaskolski and Wladek Minor 
Data collection and refinement statistics for project 5 s32 crystal crystal1

\section{model /home2/marcel/HKL/data/rerefinement/test2/5s32/structure_mr/build_model_1/hkl_import.pdb}

\begin{tabular}{|c|c|}
\hline \multicolumn{2}{|c|}{ Data collection } \\
\hline Resolution $(\AA)$ & $88.12-1.17(1.23-1.17)$ \\
\hline Wavelength ( $\AA$ ) & 0.91188 \\
\hline Space group & P43 \\
\hline a, b, c $(\AA)$ & $88.12,88.12,39.08$ \\
\hline$\alpha, \beta, \gamma\left({ }^{\circ}\right)$ & $90,90,90$ \\
\hline Completeness (\%) & 98.4 \\
\hline Reflections used & 100790 \\
\hline$<\mathrm{I}>/<$ Sigma I $>$ & 3.4 \\
\hline Redundancy & $6.3(5.2)$ \\
\hline Rmerge & $0.532 !$ \\
\hline Rpim & $0.231(5.759) !$ \\
\hline CC1/2 last shell & 0.36 \\
\hline Wilson B factor $\left(\AA^{2}\right)$ & 11.2 \\
\hline \multicolumn{2}{|l|}{ Refinement } \\
\hline Rwork / Rfree & $0.201 / 0.236$ \\
\hline Resolution $(\AA)$ & $88.12-1.17$ \\
\hline Reflections all & 88766 \\
\hline Reflections for Rfree & $4499,5.1 \%$ \\
\hline Bond lengths rmsd $(\AA)$ & 0.010 \\
\hline Bond angles rmsd $\left({ }^{\circ}\right)$ & 1.12 \\
\hline Mean B value $\left(\AA^{2}\right)$ & 18 \\
\hline Number of protein atoms & 2581 \\
\hline Mean B value for protein atoms $\left(\AA^{2}\right)$ & 15 \\
\hline Number of water atoms (expected) & $472(520)$ \\
\hline Mean B value for water atoms $\left(\AA^{2}\right)$ & 29 \\
\hline Number of ligand/ion atoms & 16 \\
\hline Mean B value for ligand/ion atoms $\left(\AA^{2}\right)$ & 24 \\
\hline Clashscore & 3.07 \\
\hline Clashscore percentile (100) & 74.8 \\
\hline Rotamer outliers (<1\%) & 0.70 \\
\hline Ramachandran outliers $(<0.2 \%)$ & 0.00 \\
\hline Ramachandran favored (>98\%) & 99.09 \\
\hline Residues with bad bonds ( $<0 \%$ ) & 0.00 \\
\hline Residues with bad angles $(<0.1 \%)$ & 0.45 \\
\hline MolProbity score & 1.10 \\
\hline
\end{tabular}

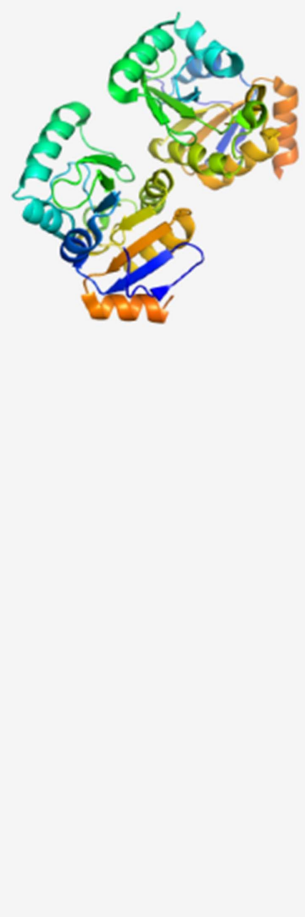




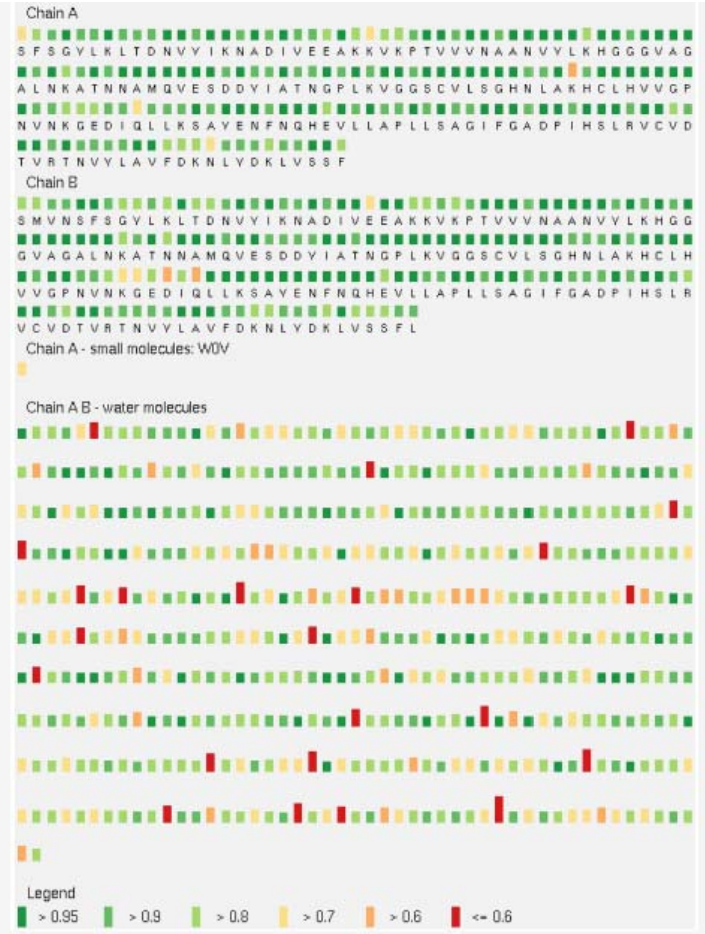

R, Rfree vs PDB average (for last 2 years)

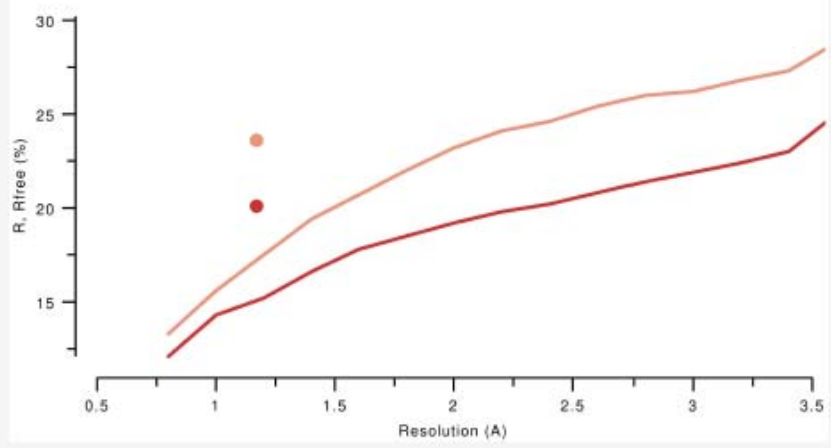

Credits:

HKL-3000

"Processing of X-ray Diffraction Data Collected in Oscillation Mode"

Z.Otwinowski, W.Minor

Methods in Enzymology, Volume 276: Macromolecular Crystallography, part A, p307-326 (1997)

"HKL-3000: the integration of data reduction and structure solution - from diffraction images to an initial model in minutes"

W.Minor, M.Cymborowski, Z.Otwinowski, M.Chruszcz

Acta Cryst. D62: 859-866 (2006)

CCP4 suite

"Overview of the CCP4 suite and current developments"

M.D.Winn et al.

Acta. Cryst. D67, 235-242 (2011)

Refmac5

"REFMAC5 for the refinement of macromolecular crystal structures"

G.N.Murshudov, P.Skubak, A.A.Lebedev, N.S.Pannu, R.A.Steiner, R.A.Nicholls, M.D.Winn, F.Long and A.A.Vagin Acta Cryst. D67, 355-367 (2011)

Coot

"Features and Development of Coot"

P.Emsley, B.Lohkamp, W.Scott, and K.Cowtan

Acta Cryst. D66, 486-501 (2010)

Figure S1 The complete structure quality report from $H K L-3000$ 


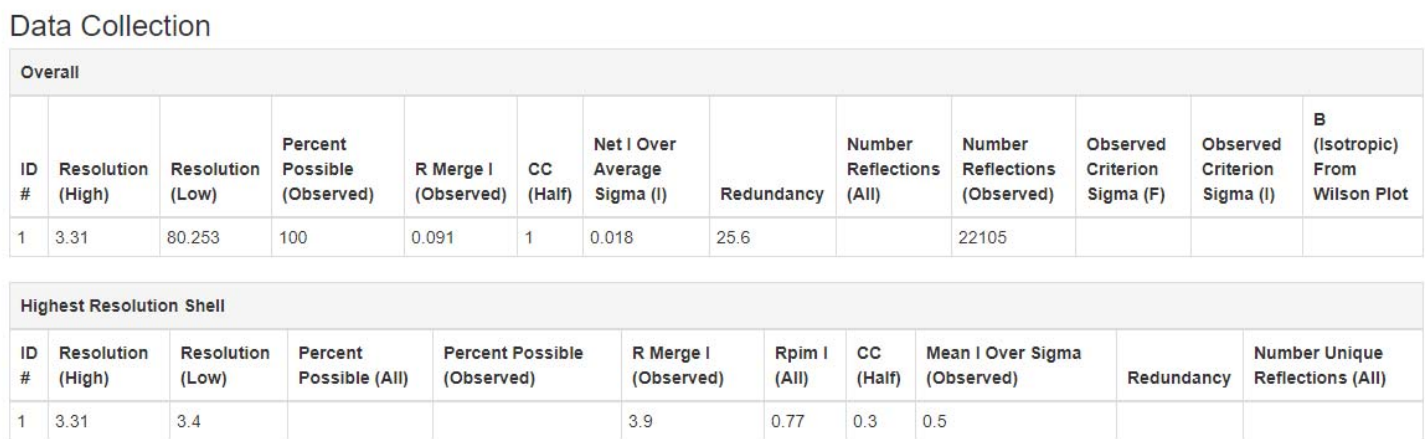

Dataset statistics

\begin{tabular}{|c|c|c|c|c|}
\hline \multirow{2}{*}{$\begin{array}{l}\text { Metric } \\
\text { Cell dimensions }\end{array}$} & \multicolumn{3}{|l|}{ Value } & \multirow{2}{*}{$\begin{array}{l}\text { Source } \\
\text { Depositor }\end{array}$} \\
\hline & $\begin{array}{l}\text { a: } 156.411 \AA \\
\text { a: } 90^{\circ}\end{array}$ & $\begin{array}{l}\text { b: } 156.411 \AA \\
\text { B: } 90^{\circ}\end{array}$ & $\begin{array}{l}\text { c: } 116.205 \AA \\
\text { y: } 90^{\circ}\end{array}$ & \\
\hline Number of reflections & \multicolumn{3}{|l|}{22065} & Xtriage(Phenix) \\
\hline Test set size & \multicolumn{3}{|l|}{$4.93 \%$} & EDS \\
\hline Data completeness & \multicolumn{3}{|l|}{$100 \%$} & EDS \\
\hline EDS resolution & \multicolumn{3}{|l|}{$3.31 \AA-80.11 \AA$} & EDS \\
\hline$\langle\mathrm{I} / \sigma(\mathrm{I})\rangle$ & \multicolumn{3}{|l|}{1.1} & Xtriage(Phenix) \\
\hline Twinning statistics & \multicolumn{3}{|c|}{$\langle|L|\rangle=0.39,\left\langle L^{2}\right\rangle=0.21$} & Xtriage(Phenix) \\
\hline Spacegroup & \multicolumn{3}{|l|}{$P 4_{2} 2_{1} 2$} & Depositor \\
\hline Possible (pseudo-) translation & \multicolumn{3}{|c|}{$\begin{array}{l}\text { The largest off-origin peak in the Patterson } \\
\text { function is } 3.12 \% \text { of the height of the origin peak. } \\
\text { No significant pseudotranslation is detected. }\end{array}$} & Xtriage(Phenix) \\
\hline Wilson B & \multicolumn{3}{|l|}{$160 \AA^{2}$} & Xtriage(Phenix) \\
\hline
\end{tabular}

Figure $S 2$ The discrepancy in the reported $<I /$ sigma(I)> values between various $w w P D B$ affiliates for the structure 6ZH9. The top of the figure is from the RCSB PDB and the bottom is from the PDBe<smiles>Cc1c(N)cccc1C(=O)NC(C)c1cccc2ccccc12</smiles><smiles>Cc1ccc(N)cc1C(=O)NC(C)c1cccc2ccccc12</smiles><smiles>C=CCNC(=O)Nc1ccc(C)c(C(=O)NCc2cccc3ccccc23)c1</smiles>

PLP_Snyder494(Y94)<smiles></smiles><smiles>Cc1ccc(CN=O)cc1C(=O)NC(C)c1cccc2ccccc12</smiles><smiles>C=CC(=O)Nc1ccc(C)c(C(=O)NC(C)C(C)(C)C[Sb])c1</smiles><smiles>CC(=O)Nc1cccc(CNC(=O)C2CCN([C@@H](C)c3cccc4ccccc34)CC2)c1</smiles>

Figure S3 Chemical structures of unique inhibitors bound in PLpro structures. The compounds are labeled with the inhibitor name as reported in the PDB title/header. The PDB ligand codes are in parentheses. 

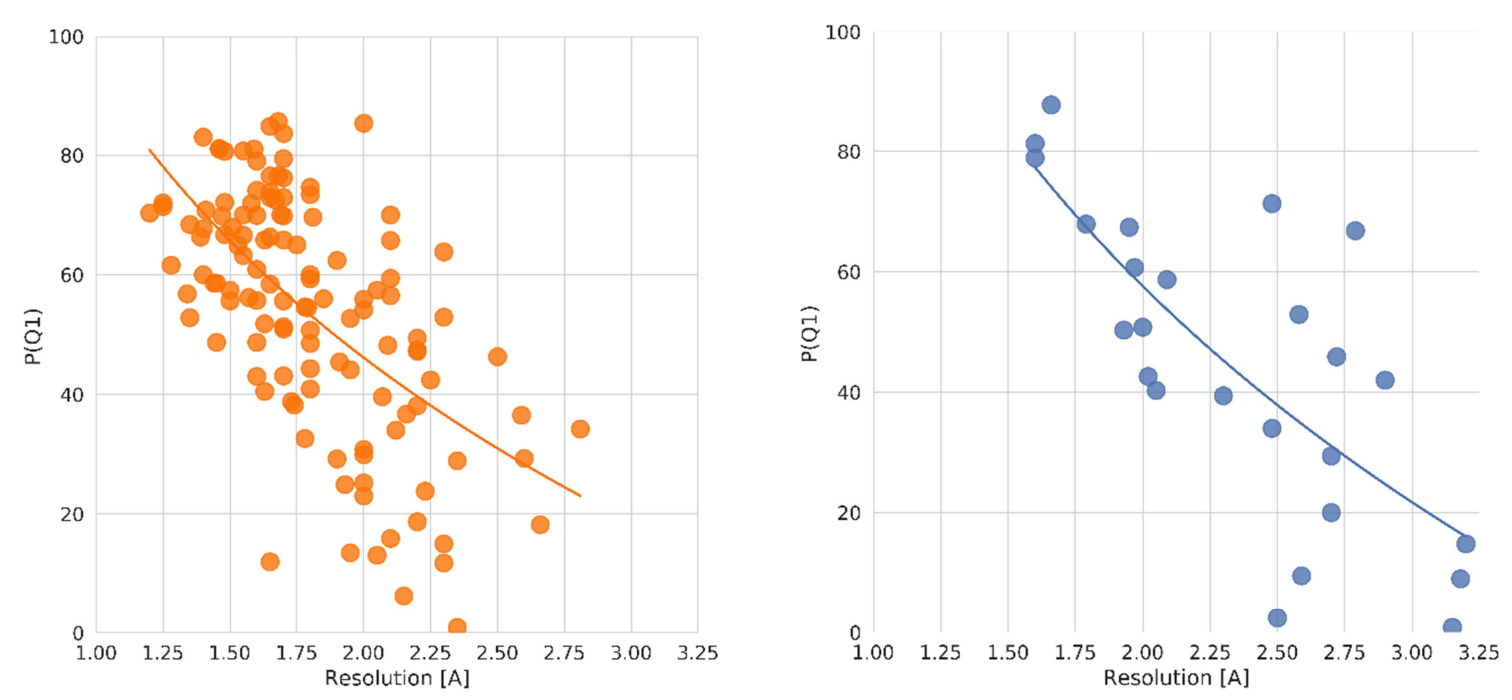

Figure S4 Plots showing the overall structure quality $P(Q 1)$ as a function of structure resolution for the main proteases (orange) and papain-like proteases (blue). It is clear that resolution cannot be the only parameter used to select the best structural model for subsequent studies, like docking or other computational studies. The lines are only for eye-guidance. 


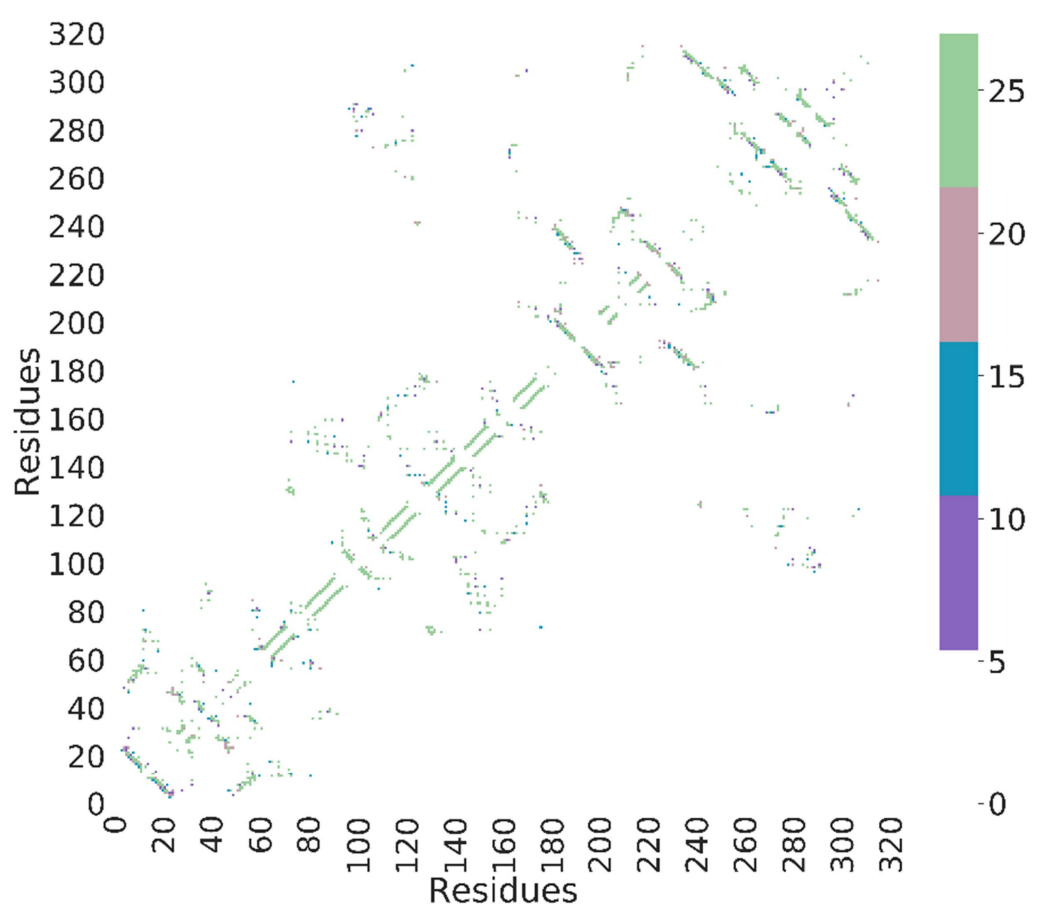

Figure S5 Contact map of residues from PLpro PDB deposits that indicates in how many models a given pair of residues are closer than 4.0 A. Contacts between two consecutive residues are excluded. 


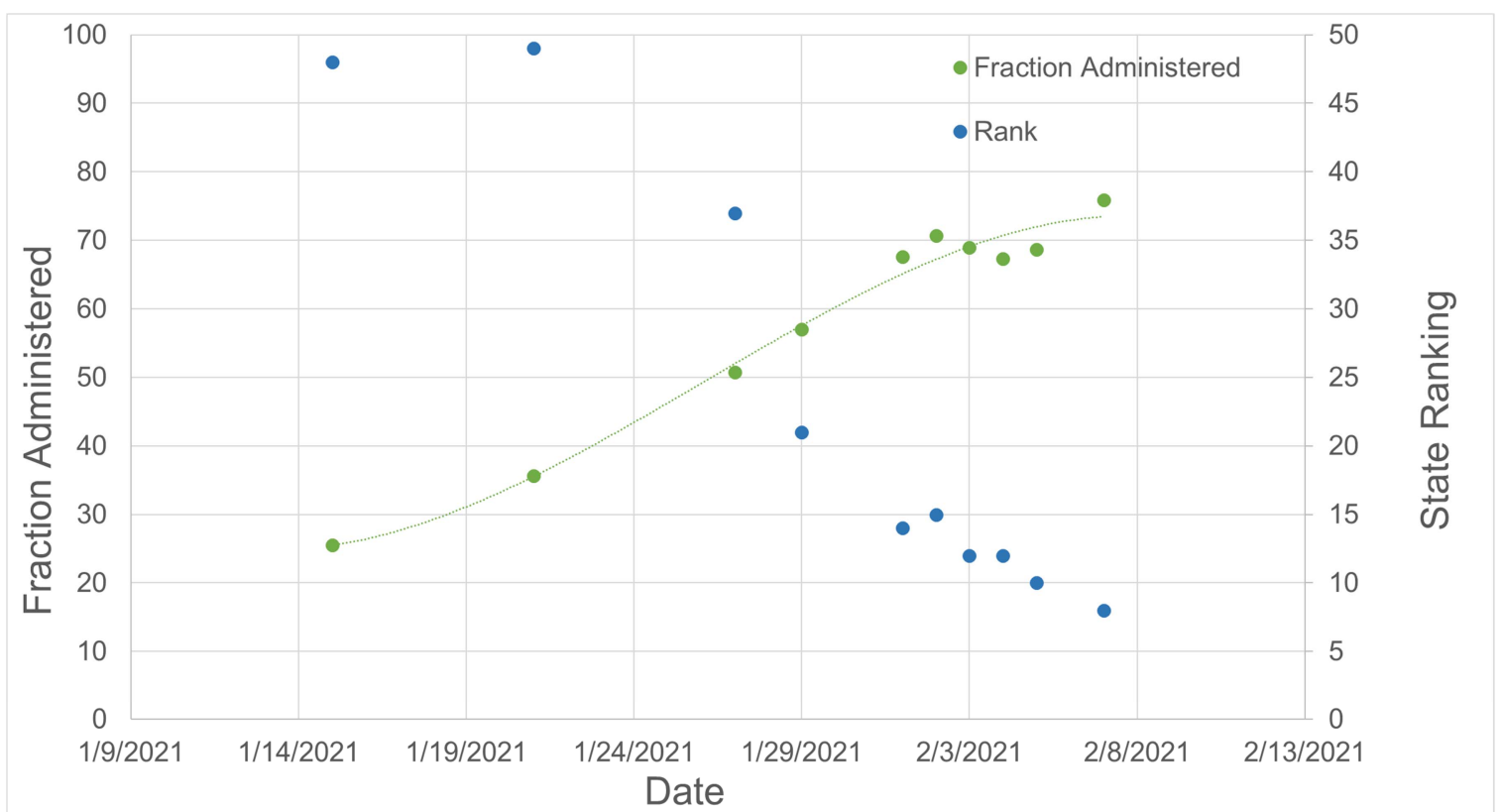

Figure S6 Vaccine Distribution and Administration in the Commonwealth of Virginia, USA. The blue circles represent the rank of efficiency defined as the fraction of distributed vaccine doses that were administered on a given date. Green circles represent the efficiency, which exceeded $80 \%$ as of 2/9/2021. On that date, Virginia ranked number one in efficiency among states that had administered more than 1 million vaccine doses. As the vaccination data are updated regularly, the current Commonwealth of Virginia efficiency is presented at https://virginia.bioreproducibility.org. Source: https://www.beckershospitalreview.com/public-health/states-ranked-by-percentage-of-covid-19vaccines-administered.html and New York Times. 